\title{
A CONSTRUÇÃO DE CONCEITOS SOBRE GESTÃO E TRATAMENTO DE RESÍDUOS QUÍMICOS: UMA EXPERIÊNCIA DE FORMAÇÃO DE ESTUDANTES DE QUÍMICA
}

\author{
Diego B. de Oliveira ${ }^{a}$, Raquel W. Becker ${ }^{\text {, }}$, Carla Sirtoria e Camila G. Passos ${ }^{\mathrm{a}, *,(1)}$ \\ anstituto de Química, Universidade Federal do Rio Grande do Sul, CEP 91501-970, Porto Alegre - RS, Brasil
}

Recebido em 04/09/2019; aceito em 27/11/2019; publicado na web em 10/02/2020

\begin{abstract}
THE CONSTRUCTION OF CONCEPTS ON THE MANAGEMENT AND TREATMENT OF CHEMICAL WASTE: A TRAINING EXPERIENCE OF CHEMISTRY STUDENTS. This work aims to analyze the contribution of a training action to the awareness and improvement of the knowledge of students of Chemistry and Chemical Engineering of Universidade Federal do Rio Grande do Sul (UFRGS) courses, regarding the processes of management and treatment of chemical wastes and wastewater generated in the experimental course. The research was performed with 66 students enrolled in the Experimental General Chemistry subject in the second semester of 2017. For that purpose, a two-hour lesson action training course was offered. As data collecting tools, an Initial Questionnaire was applied before the training stage and a Final Questionnaire was applied after the training stage. In order to do the analyses of the questionnaire answers, were elaborated also images about the frequency of the words by using NVivo $12^{\oplus}$ software. The data set indicates a scientific inculturation/alphabetization of concepts by students in terms of the main treatment types used to mitigate residues that are generated in teaching labs, as Coprocessing, Incineration and Sanitary Landfill. It can also be inferred that the activity offered to the students contributed to the formation of values necessary for the formation of professionals more aware of their performance in society.
\end{abstract}

Keywords: chemical waste; treatment; management; environmental education.

\section{INTRODUÇÃO}

Atualmente, no contexto internacional há uma tendência crescente no que diz respeito à conscientização dos sujeitos sobre seu papel de pertencentes, atuantes e impactantes do meio ambiente..$^{1-3}$ Essa noção de protagonismo ambiental traz também a necessidade de que se busquem formas de se manter um equilíbrio com todas as espécies envolvidas. ${ }^{4-6}$

As Universidades brasileiras, principalmente as públicas, cientes de sua responsabilidade social e ambiental, foram pioneiras na elaboração de ações para mitigar o descarte incorreto dos resíduos. ${ }^{3,7}$

Até o início da década de 1990, as disciplinas experimentais que produziam resíduos químicos apresentavam como forma de destinação final o descarte diretamente em pias para os resíduos no estado líquido e no lixo comum para aqueles em estado sólido., Essas práticas antigas ofereciam grandes riscos, tanto à população como ao meio ambiente, visto que a diversidade e periculosidade dos resíduos gerados eram elevadas, mesmo que o seu volume fosse menor quando comparados aos resíduos gerados, por exemplo, pelo setor industrial. ${ }^{9-12}$ Concomitantemente à legislação ambiental ${ }^{13,14} \mathrm{e}$ recomendações internacionais, ${ }^{1,6}$ identificou-se também a crescente necessidade de se desenvolver em todos os níveis de ensino práticas relacionadas à Educação Ambiental, ${ }^{15,16}$ almejando uma maior conscientização de todos envolvidos sob suas responsalibidades quanto à preservação do ambiente.

Frente ao exposto, ao final da década de 1990 e início dos anos 2000, as Universidades passaram a ajustar suas práticas às necessidades de uma sociedade mais consciente e sustentável, e para tal foram criados Programas de Gestão de Resíduos (PGR) de acordo com as especificidades de cada local, para que os hábitos antigos de descarte incorretos não se mantivessem., ${ }^{3,7-12}$

A criação de um PGR, que necessita de apoio institucional irrestrito e colaboração de toda comunidade acadêmica (alunos,

*e-mail: camila.passos@ufrgs.br professores, técnicos, etc), percebe-se a necessidade de mudanças de atitudes de forma coletiva, para que sejam alcançados os objetivos de forma eficiente. ${ }^{3,12}$ De modo geral, antes do advento dos PGR's as Universidades não apresentavam grande estoque de resíduos passivos (aqueles não caracterizados), dado que os mesmos eram descartados de forma indiscriminada, porém, com a implementação de um PGR esse passivo passou a ser analisado para, posteriormente, ser classificado e então receber a destinação final adequada. ${ }^{9,10}$ Visando extinguir os resíduos passivos, criam-se rótulos padrões para que seja mais fácil o gerenciamento e em seguida o pré-tratamento possível e/ou descarte adequado de acordo com a classificação do resíduo. ${ }^{711}$ Por tal motivo, depois de implementado o PGR, este deve ser constantemente revisitado e reformulado sempre que necessário, atendendo às novas demandas que surgirem com o passar do tempo.,12

Nessa realidade está inserido o presente estudo, que visa analisar as potencialidades de uma ação de formação para tomada de consciência e aperfeiçoamento dos conhecimentos de estudantes dos cursos de Bacharelado em Química, Química Industrial e Engenharia Química da UFRGS quanto aos processos de gestão e tratamento de resíduos químicos gerados nas aulas experimentais. Este trabalho compõe uma das etapas de uma investigação realizada em nível de mestrado que visou a retroalimentação ${ }^{12}$ do projeto nomeado "Ensino e a Química Limpa". ${ }^{7}$ O referido projeto foi implementado em 1998 e possuía como objetivo central a formação de profissionais em química preocupados com a qualidade e conservação do meio ambiente, além de visar o desenvolvimento e utilização de tecnologias limpas. ${ }^{7}$

Para tanto, considera-se a perspectiva da Educação Ambiental (EA) Crítica. ${ }^{5} \mathrm{O}$ ponto de partida para determinar a EA como crítica é seu desassossego com as concepções socioambientais das relações humanas, ou seja, com as relações que os indivíduos concebem entre si e com o ambiente onde interagem, assimilando-os de modo crítico e transformador. ${ }^{5,17}$ Nesse sentido, a teoria crítica na EA apresenta a finalidade maior de formar cidadãos que possam transformar a sociedade em que vivem. ${ }^{18,19}$ 
Resultante de um modo de produção majoritariamente capitalista em que o mundo se encontra, a degradação ambiental se intensifica continuamente em nossa sociedade. Dessa maneira, surge a necessidade de uma EA crítica, garantindo propostas e projetos que visam rigor teórico e aprofundamento reflexivo sobre seus fundamentos, e que realmente possa tornar as pesquisas em EA relevantes para a comunidade.$^{5,17}$ Essa necessidade de estudos ambientais, que realmente propicie um pensamento crítico e reflexivo nas pessoas, torna-se ainda mais necessária no espaço acadêmico. ${ }^{19}$

Partindo destes pressupostos, entende-se que "A tomada de consciência passa pelos portões dos conceitos científicos" (p. 290). ${ }^{20}$ Assim, a tomada de consciência e sistematização de conceitos estão imbricadas, ou seja o desenvolvimento da conscientização está intimamente ligado à generalização e/ou a formação de um conceito superior. ${ }^{20}$ Logo, para atingir o espectro de trasnformação do meio social, o processo de ensino e aprendizagem dos conceitos científicos assume papel primordial para a formação da consciência dos futuros profissionais da área da Química, considerando que o meio acadêmico possibilita vivências que serão projetadas para os campos de atuação destes profissionais..$^{18,19}$

\section{FUNDAMENTAÇÃO TEÓRICA}

\section{Gerenciamento de resíduos}

Em quaisquer processos de obtenção ou transformação de materiais são gerados, além dos produtos de interesse, produtos que não ostentam valor comercial, benefício ou utilidade para o ser humano. Esses produtos inservíveis são chamados de resíduos. Os resíduos podem ser classificados em não perigosos, perigosos, passivos ou ativos, e de acordo com sua classificação, quando descartados de forma inapropriada, são capazes de contaminar as águas (superficiais, subterrâneas, etc.), o solo, os sedimentos, o ar e, até mesmo, os seres humanos. ${ }^{21}$

Grande parte das instituições de ensino e de pesquisa é também responsável pela produção de resíduos químicos. Esses tipos de resíduos necessitam de grande atenção, visto que, se comparados aos resíduos industriais ou até mesmo domiciliares, possuem volume menor, mas apresentam grande diversidade, o que os tornam de difícil descarte, visto que não há uma forma de realizar um tratamento "padrão". ${ }^{3}$ Além disso, o descarte indevido/incorreto dado a estes resíduos é responsável pela contaminação dos diferentes compartimentos ambientais, resultando assim em situações de poluição ambiental. ${ }^{2}$ Para evitar tais impactos, as Universidades estão cada vez mais, ou pelo menos deveriam estar, buscando soluções para conseguir minimizar ao máximo os riscos ambientais causados pelos resíduos gerados em suas atividades. ${ }^{3,4}$

Nesse sentido, conforme indicado por Gerbase et al., ${ }^{8}$ é recomendado, a partir da Carta de Niterói (documento elaborado no $3^{\circ}$ Encontro Nacional de Segurança em Química ocorrido na Universidade Federal Fluminense em 2004), que as Instituições formulem ações de gerenciamento de resíduos a fim de atender às legislações ambientais vigentes. Desde 1990 houve uma preocupação em vários países do mundo com a busca por melhorias para tentar diminuir os impactos causados pelo incorreto descarte de resíduos ou até mesmo implementar novos processos de tratamento. ${ }^{3,8}$

A problemática em relação aos resíduos gerados nos laboratórios é um assunto mundialmente discutido. Várias alternativas que almejam o desenvolvimento sustentável das ações de pesquisa e ensino estão sendo colocadas em prática, como a implementação de PGR e redução na geração de resíduos pelos laboratórios das Instituições de Ensino. ${ }^{3}$

No Brasil, tentativas nesse sentido vêm sendo praticadas desde 1990, majoritariamente em algumas das mais antigas e maiores universidades públicas e privadas. ${ }^{7-12} \mathrm{~A}$ apreensão com a temática ambiental faz com que o gerenciamento de resíduos seja um processo de grande importância na defesa da qualidade do meio ambiente e da saúde. A gestão compartilhada de resíduos deve levar em conta primeiramente a não geração, a redução da geração e o reaproveitamento dos resíduos, objetivando evitar os efeitos de degradação do meio ambiente. ${ }^{12}$

De modo geral, o tratamento e a gestão de resíduos tornam-se um problema que é capaz, em algumas ocasiões, de alcançar graves dimensões e/ou ser ignorado a um plano secundário. Na maior parte das ocorrências os resíduos químicos, por exemplo, são armazenados de forma inapropriada e acabam convertendo-se em passivos ambientais, os quais permanecem depositados, apropriada ou inapropriadamente, até a sua destinação final, isso quando são armazenados. ${ }^{3,8}$

Há mais de vinte anos o IQ/UFRGS realiza programas piloto para coleta, transporte e tratamento de resíduos, tanto os orgânicos quanto os inorgânicos. Esse tipo de iniciativa é pioneira entre as Universidades do Brasil. ${ }^{8}$ Em 2001, foi criado o "Centro de Gestão e Tratamento de Resíduos Químicos" - CGTRQ, sendo este um Órgão Auxiliar do Instituto de Química da UFRGS, com o propósito de ser uma entidade de destaque, que se dedica à construção e à propagação de conhecimentos científicos e tecnológicos na área ambiental, em especial na gestão de resíduos químicos e de segurança química. ${ }^{7}$ O CGTRQ passou a funcionar em 15 de julho de 2002 e os serviços prestados pelo CGTRQ vão desde a visita técnica para reconhecimento do Gerador; formulação de planejamento e criação de padrões para retirar o passivo químico, adequação de um plano de coleta de acordo com a demanda, oferecimento de curso para capacitação dos usuários com relação às ações do sistema de coleta de resíduos químicos, onde esta explanação se dá de forma teórica e in loco, além de definir as medidas para o correto transporte dos resíduos entre os Campi da UFRGS e dentro do Campus. O CGTRQ assume responsabilidade técnica dos serviços do gerador até o destino final, emitindo os documentos legais que são necessários em conformidade com a legislação ambiental vigente (Nota Fiscal, MTR, Ficha de Emergência). Além disso, o CGTRQ realiza o encaminhamento dos resíduos que não podem ser tratados in loco, para empresas parceiras, que realizam os processos de coprocessamento, incineração ou disposição em aterro sanitário. ${ }^{22}$

\section{Educação ambiental}

As aflições humanas com respeito ao meio ambiente existem nas diversas sociedades há algumas décadas. Mesmo que tenha sido na década de 1980 que ocorreu a popularização da questão ambiental, o movimento ecológico, como um movimento social global, data os anos 1960. Os discursos ambientalistas, porém, não são recentes, pois no século 18 já afloravam na Inglaterra. ${ }^{18}$

Entretanto, a incorporação da EA como método para almejar sociedades ambientalmente mais conscientes e responsáveis não é uniforme. Há variados princípios, estratégias e objetivos para aqueles que a exercitam, definindo, do ponto de vista conceitual, diferentes abordagens educativas. Tozoni-Reis ${ }^{5}$ distingue algumas das possíveis abordagens como: Disciplinatória-moralista; Ingênua-imobilista; Ativista-imediatista; Conteudista-racionalista; Crítica-transformadora.

Essas distintas abordagens de EA apontam concepções transformadoras ou perspectivas adaptadora-reprodutoras. A visão adaptadora é definida pela ideia de que a EA possui como incumbência a "adaptação" dos cidadãos a um "renovado" padrão de sociedade que, apesar de mais inquieto com a temática ambiental, não indaga o modelo de desenvolvimento em curso. ${ }^{17}$

Entretanto, nesse trabalho defende-se a perspectiva da EA crítica. Como destaca Tozoni-Reis ${ }^{17}$ (p. 75), a perspectiva crítica considera “a 
educação ambiental como um processo político de apropriação crítica e reflexiva de conhecimentos, atitudes, valores e comportamentos que têm como objetivo a construção de uma sociedade sustentável nas dimensões ambiental e social".

De acordo com Tozoni-Reis, ${ }^{17}$ a origem da ação educativa ambiental é o movimento de fazer-se plenamente humano pela apropriação e/ou transmissão crítica e transformadora da totalidade histórica e concreta da vida dos seres humanos no meio ambiente. Segundo a autora, esse processo educativo ambiental faz a mediação da apropriação, pelos sujeitos, das qualidades e capacidades fundamentais à ação transformadora responsável diante do ambiente em que vivem. ${ }^{5,17}$

Nesse contexto, a educação crítica situa-se no horizonte da ação política da educação voltada para a transformação social, que, historicamente, coloca-se em uma grave crise socioambiental. ${ }^{17,19}$

Acredita-se que a finalidade precípua da Universidade é desenvolver a formação sólida dos estudantes, por intermédio de uma aprendizagem que privilegie experiências vividas por estes e os faça refletir profundamente sobre a realidade que os cerca, contribuindo assim para que possam se tornar cidadãos críticos e reflexivos. Uma EA crítica e reflexiva adquire especial relevância quando se tem em vista o contexto social em que os estudantes vivem.

Frente aos apontamentos destacados neste texto sobre a EA crítica, percebe-se que a conscientização supera a apropriação ou enculturação $0^{23}$ de conhecimentos sobre gestão e tratamento de resíduos. Todavia, considera-se que a tomada de consciência ${ }^{19}$ só será concretizada quando os estudantes refletirem sobre os conhecimentos construídos e conseguirem relacioná-los com os aspectos políticos, sociais, econômicos e ambientais a respeito dos reais perigos que os resíduos químicos, foco de estudo deste trabalho, podem causar aos seres humanos e ao meio ambiente. Nesse âmbito, salienta-se que os egressos dos cursos Bacharelado em Química, Química Industrial e Engenharia Química possivelmente terão que manusear e gerenciar diferentes tipos de resíduos químicos. Assim, entende-se a pertinência do desenvolvimento de estudos e ações formativas que promovam a compreensão sobre os elementos dos processos de tomada de consciência sobre gestão e tratamento de resíduos, tanto cotidianas no meio laboral (laboratórios de ensino) como fora dele (meio industrial) alicerçados numa perspectiva da EA crítica.

\section{A construção de conceitos científicos}

Driver et al. ${ }^{23}$ apresentam que a construção do conhecimento científico é favorecida quando as rotinas de sala de aula fundamentam-se em uma perspectiva sociointeracionista. Nesse sentido, as atividades devem priorizar a discussão entre estudantes e professor para que, em conjunto, possam reorganizar as teorias pessoais (conhecimento espontâneo, prévio ou senso comum) dos aprendentes. Conforme os autores, ${ }^{23}$ “ $[\ldots]$ o conhecimento e o entendimento, inclusive o entendimento científico, são construídos quando os indivíduos se engajam socialmente em conversações e atividades sobre problemas e tarefas comuns." (p. 34).

Nessa concepção de ensino e aprendizagem de ciências, o papel do professor é o de organizar o processo pelo qual os indivíduos geram significados sobre os fenômenos que são estudados. O professor é o orientador dos aprendizes, para que estes consigam atribuir sentido pessoal à maneira como os conhecimentos científicos são gerados e validados. ${ }^{24}$ Nesse sentido, atribuir significado é um processo dialógico, onde "os indivíduos são introduzidos em uma cultura por seus membros mais experientes. À medida que isso acontece, eles 'apropriam-se' das ferramentas culturais por meio do seu desenvolvimento nas atividades dessa cultura" (p. 34). ${ }^{23}$

Assim, considera-se que o propósito da educação científica, e consequentemente da EA, não é o de eliminar os conhecimentos que os alunos já possuem, mas sim de possibilitar a sua enculturação. ${ }^{23}$ Enfim, incorporar novos símbolos e culturas aos conhecimentos existentes, pluralizando estes conceitos, para que possam ser utilizados em distintos momentos e situações, conforme o meio cultural/social em que o aluno se encontra. ${ }^{23}$

Com essas premissas, a aprendizagem de ciências envolve a introdução em um mundo simbólico, o contato com novas culturas, a divergência de ideias, para assim favorecer a enculturação dos conceitos. Considerando a teoria sociocultural de aprendizagem de Vigotski ${ }^{21}$ compreende-se o papel dos conceitos espontâneos na elaboração dos conceitos científicos, pois é na dinâmica de desenvolvimento e interação mútua desses conceitos, em sala de aula, que se pode favorecer a aprendizagem dos estudantes.

Entretanto, o processo de ensino e aprendizagem focado na enculturação engloba alguns obstáculos. As dificuldades iniciam com o conflito gerado quando a cultura científica que o professor representa e apresenta diverge do conhecimento prévio dos alunos. ${ }^{24}$ Os estudantes normalmente utilizam os conhecimentos desenvolvidos em suas experiências pessoais e sociais para explicar os fenômenos do cotidiano. Esses esquemas de conhecimento informais são adequados, muitas vezes, para interpretar as experiências do dia a dia. Todavia, a cultura científica difere do senso comum na sua entidade ontológica e epistemológica, pois apresenta natureza diferente e utiliza símbolos, teorias, modelos e representações específicas para analisar e explicar os fenômenos naturais. "Em outras palavras, as estruturas ontológicas cotidianas da criança desenvolvem-se com a experiência e com a utilização da linguagem dentro de uma cultura." (p. 35). ${ }^{23}$

Frente a essa compreensão, ensinar ciências não é apenas ampliar ou organizar os conhecimentos dos alunos sobre os fenômenos a partir de atividades que gerem conflitos de ideias. A aprendizagem de ciências engloba o processo de socialização "em maior ou menor grau, nas práticas da comunidade científica, com seus objetivos específicos, suas maneiras de ver o mundo e suas formas de dar suporte às assertivas do conhecimento" (p. 36). ${ }^{23}$

Para tanto, os estudantes devem envolver-se em um processo pessoal de construção e de atribuição de significados. ${ }^{19,23,24}$ Assim, aprender ciências envolve tanto processos pessoais como sociais. No plano pessoal, os alunos desenvolvem significados próprios dentro do contexto social da sala de aula, para apropriar-se dos conhecimentos científicos. No plano social, o indivíduo é apresentado aos conhecimentos científicos, no entanto não no sentido de abandonar os seus de senso comum. As pessoas atuam em diferentes comunidades ou contextos sociais, nas quais podem optar pelo uso da linguagem científica ou do cotidiano. O foco principal está na compreensão de que o conhecimento científico é socialmente construído, validado, comunicado $^{23}$ e que pode ser falível e não neutro, pois é uma construção humana. ${ }^{18}$

Para os educadores de ciências a provocação está em difundir, entre os alunos, uma perspectiva crítica sobre a cultura científica. ${ }^{19,23,24}$ Neste viés de pensamento, Chassot ${ }^{18}$ aponta que a responsabilidade maior do professor ao ensinar Ciências é possibilitar a transformação dos alunos em cidadãos mais críticos, para que estes possam melhorar o mundo. Diante de tal objetivo, é pertinente esclarecer que o autor defende uma proposta para a educação: a da alfabetização científica.

Para Chassot (p. 62), ${ }^{18}$ a alfabetização científica pode ser vista "como o conjunto de conhecimentos que facilitariam aos homens e mulheres fazer uma leitura do mundo onde vivem[...]". Enfim, são os conhecimentos científicos mínimos necessários para que as pessoas possam exercer seus direitos na sociedade.

Sasseron e Carvalho (p.61) $)^{25}$ consideram que a alfabetização científica possibilita aos alunos "interagir com uma nova cultura, com uma nova forma de ver o mundo e seus acontecimentos, podendo modificá-los e a si próprio através da prática consciente propiciada 
por sua interação cerceada de saberes de noções e conhecimentos científicos[...]".

Nesse sentido, os pesquisadores da área defendem que a Alfabetização Científica é necessária para que os cidadãos utilizem os conhecimentos científicos para tomar decisões na vida cotidiana, que possam compreender como os conhecimentos foram construídos, para assim participarem de discussões sobre temáticas que envolvam tecnologia e ciência. ${ }^{18,25}$

Entretanto, as pessoas não ligadas à área das Ciências argumentam que não precisam dos conhecimentos das ciências para tarefas simples do cotidiano como o uso de sabões e detergentes. Conforme Chassot, ${ }^{18}$ muitos estudantes da área não conhecem sobre a história da Ciência e a construção dos conhecimentos, o que facilitaria o processo de alfabetização científica. Todavia, o autor ${ }^{18}$ enfatiza que ser alfabetizado cientificamente é saber interpretar a linguagem em que está escrita a natureza, já que a Ciência foi construída pelos homens para explicar o mundo do qual fazem parte.

No contexto deste trabalho, entende-se que a discussão e orientação sobre os tipos de resíduos, formas de armazenamento e rotulagem, tratamentos e riscos possam contribuir para a alfabetização científica dos estudantes da disciplina de Química Geral Experimental quanto à gestão e tratamento de resíduos químicos.

Como apontam os referenciais que fundamentam este trabalho, ${ }^{5,17-19}$ com as tentativas de modificações de práticas e posturas de ações cotidianas pode-se almejar novos valores quanto à preservação do ambiente. Os autores sugerem envolver os estudantes em atividades de EA focadas em temáticas sociais, políticas e econômicas. Assim, os sujeitos poderão exercer sua cidadania com postura crítica na busca de melhorias do ambiente natural. ${ }^{5,17-19}$

\section{Percurso metodológico}

A investigação realizada nesta pesquisa tem natureza qualitativa. ${ }^{26}$ Ao interpretar o processo de pesquisa como um mosaico que descreve um fenômeno complexo a ser compreendido, Günther ${ }^{26}$ justifica a associação da análise hermenêutica da pesquisa qualitativa, através do estudo de documentos, sujeitos e contextos, com a clareza da interpretação dos dados numéricos (frequências, medidas, desvios) da pesquisa quantitativa e da sua possibilidade de generalizações. O autor $^{26}$ ainda pondera que o pesquisador, enquanto participante do processo de construção de conhecimento, idealmente, não deveria escolher entre um método ou outro, mas utilizar as várias abordagens, qualitativas e quantitativas que se adéquam à sua questão de pesquisa.

Nesse sentido, para verificar o nível de conscientização dos sujeitos participantes desta investigação sobre a gestão e o tratamento de resíduos, foi utilizado um instrumento diagnóstico inicial com questões abertas e fechadas para um total de 66 alunos dos cursos de Bacharelado em Química, Química Industrial e Engenharia Química que estavam matriculados na disciplina de Química Geral Experimental no segundo semestre de 2017.

Esse instrumento inicial foi aplicado na primeira semana de aula de nove turmas de Química Geral Experimental, cerca de dois meses antes da data que ocorreu a ação de formação. A atividade formativa foi oferecida como uma ação de extensão registrada junto à Pró-Reitoria de Extensão da UFRGS, com o título "Formação sobre Gestão e Tratamento de Resíduos para Graduação". A proposta foi conscientizar sobre as contribuições do CGTRQ para a manutenção de práticas sustentáveis nesta instituição e dos encaminhamentos necessários para o correto tratamento dos diferentes tipos de resíduos gerados nos laboratórios de ensino e pesquisa.

A ação foi realizada na disciplina de Química Geral Experimental (QUIP01003), pois esta é ofertada nos primeiros semestres letivos para os cursos com ênfase em Química. No curso, foram apresentadas aos alunos as atribuições profissionais registradas junto ao Conselho Regional de Química que os cursos de Química e Engenharia Química possibilitam, as diferentes classificações existentes para os resíduos químicos, a evolução da legislação ambiental brasileira, assim como de Educação Ambiental, além dos tratamentos possíveis para os quais são encaminhados os resíduos pelo CGTRQ, a fim de dar a destinação final adequada a tais rejeitos.

A formação teve duração de 45 minutos em cada turma, onde inicialmente se fez a apresentação sobre a evolução histórica da legislação ambiental brasileira, tanto em termos de responsabilidades civil e penal, como sobre Educação Ambiental em todos os níveis de ensino. A partir de tal evolução buscou-se a relação com as responsabilidades legais de cada um na Universidade, seja como aluno, como professores e demais funcionários, e, posteriormente foram apresentados os tratamentos encaminhados pelo CGTRQ juntamente com suas respectivas quantidades e valores gastos para cada tipo de encaminhamento, a saber, os tratamentos trabalhados foram: coprocessamento, incineração e aterro industrial.

A atividade formativa ocorreu de forma expositiva-dialogada. Buscou-se com essa metodologia que os alunos pudessem expor suas ideias e conceitos a respeito desta temática, podendo assim, posteriormente, constatar a enculturação dos significados atribuídos aos conceitos tratados durante a formação oferecida. Durante os momentos de discussão foram levantados alguns questionamentos e contribuições por parte dos estudantes como: o processo de reciclagem do óleo de soja usado; o uso de plantas para biorremediação; o tipo de sanção penal para crimes ambientais; as atribuições específicas de cada formação na área da química.

Depois de transcorridos dois meses da ação de formação, foi aplicado um instrumento diagnóstico final com questões abertas e fechadas, para verificar a enculturação dos conhecimentos dos estudantes sobre os processos de gestão e tratamento de resíduos.

Para as questões abertas foi utilizado o software NVivo $12^{\circledR}$ que permitiu a construção de imagens onde as palavras apresentam tamanho proporcional com a frequência, ou seja, quanto mais a palavra se repetir nas respostas dos alunos, maior será o tamanho da fonte utilizada na construção da imagem. Para o uso do software foi feita a transcrição das respostas dos alunos, e após transferir para o software foram criadas as imagens para cada questão analisada. As imagens geradas para as respostas dos instrumentos de diagnóstico inicial e final foram comparadas para permitir a análise desejada. Buscou-se, assim, diagnosticar se ocorreu evolução conceitual por parte dos estudantes, ou seja, se ocorreu a enculturação $0^{23}$ de conceitos discutidos durante a atividade de formação oferecida.

A utilização do software para a análise das respostas dos alunos permitiu gerar informações quanto ao grau de frequência das palavras utilizadas, podendo assim realizar uma análise com maior diversidade de fonte de dados, sejam eles numéricos ou descritivos. ${ }^{27}$ Além disso, possibilitou a análise comparativa entre os instrumentos de diagnóstico inicial e final.

\section{RESULTADOS E DISCUSSÃO}

\section{Perfil dos estudantes e conceitos iniciais}

A partir da análise do diagnóstico inicial evidenciou-se um perfil de jovens ingressantes nos cursos de cursos de Química Industrial, Bacharelado em Química e Engenharia Química, onde dos 66 respondentes iniciais, 52 deles possuiam idade entre 17 e 20 anos, o que está de acordo com o esperado para uma disciplina oferecida na etapa inicial da graduação.

Quanto à experiência profissional, apenas 13 alunos indicaram a vivência de alguma atividade. Dentre as funções desempenhadas 
por tais estudantes, pode-se destacar: técnico em Química, técnico de laboratório, assistente de laboratório em escola, controle de qualidade, técnico de análises clínicas, estágio em Química Ambiental, estágio técnico. Dos 13 alunos que possuíam experiência, 6 indivíduos disseram que esta era de até 1 ano, enquanto outros 5 afirmaram ter vivências profissionais superiores a 1 ano.

Quando se analisa as respostas relacionadas ao nível de formação dos estudantes, constata-se que dos 66 respondentes, 15 alunos já possuíam estudos prévios: 13 estudantes apresentavam formação como técnicos e os outros 2 alunos declararam ser tecnólogos em Gestão Ambiental, ou seja, tecnólogo de nível superior. Dos que informaram possuir curso técnico, 9 respondentes eram técnicos em Química. Esse perfil de formação converge com as respostas obtidas na questão relativa às experiências profissionais.

Sobre os principais tratamentos utilizados para disposição final de resíduos sólidos, inicialmente os estudantes foram questionados quanto ao coprocessamento. Para essa pergunta, 62 dos 66 participantes do instrumento de diagnóstico inicial afirmaram não ter conhecimento sobre este tratamento.

Dos 4 alunos que afirmaram possuir conhecimento sobre coprocessamento, 2 apresentaram significado que se aproxima ao encontrado na literatura, a saber:

$\mathrm{R}(02)$ : "Reprocessar os produtos/reagentes que "sobram" da operação, para obter melhor produtividade.";

$\mathrm{R}(04)$ : "Utilização de um resíduo, algo descartado que sofre um processo para transformação de outro material.”.

O coprocessamento é utilizado para tratar resíduos tipo Classe II, ${ }^{21}$ que são sólidos e solventes orgânicos não halogenados, e que possam gerar energia e matéria-prima como substituintes de outras. ${ }^{28}$

Já em relação à incineração, tratamento utilizado pelo CGTRQ para encaminhar os resíduos sólidos do tipo Classe-I, ${ }^{21} 49$ alunos afirmaram conhecer. Desses 49, 45 alunos apresentaram algum significado para o conceito, porém 34 ficaram limitados ao fato de queimar o resíduo. Acredita-se que esta maioria vinculou-se aos primeiros significados que a palavra incineração nos remete. De certa forma na incineração ocorre a queima, mas cientificamente existem alguns critérios a serem considerados além da simples decomposição térmica dos materiais. A incineração é o processo no qual os resíduos químicos são decompostos por oxidação térmica a altas temperaturas $\left(1200^{\circ} \mathrm{C}\right)$ objetivando destruir a fração orgânica do resíduo e reduzir o seu volume, com o uso de equipamentos para minimizar a emissão de gases e os impactos relacionados a estes. ${ }^{28}$

Para 7 estudantes, os significados do conceito, mesmo sendo superficiais, estavam mais próximos ao aceito pela literatura para incineração, como pode ser observado a partir da leitura da resposta abaixo.

\section{R(41): "Queima integral do material.".}

Quatro alunos apresentaram significados para incineração de forma coerente com o conceito científico ou utilizou exemplo de resíduo encaminhado para este tipo de tratamento, como é observado:

R(47): "Resíduos são incinerados e é dado um destino para o gás.";

$\mathrm{R}(48)$ : "Queima completa de resíduos em ambiente controlado para impedir contaminação.”.

Sobre os Aterros Sanitários, dos sujeitos que participaram da pesquisa, 54 afirmaram saber o que são, sendo que destes, 38 apresentaram significado coerente com o conceito científico para esse tipo de disposição. Os Aterros Sanitários deveriam ser utilizados de acordo com a Política Nacional de Resíduos Sólidos (PNRS ${ }^{29}$ como forma de disposição final para maioria dos resíduos sólidos orgânicos gerados pela população. Em 16 respostas os alunos apresentaram significados de forma muito simplificada. Por exemplo, percebe-se que as respostas estão relacionadas ao Aterro Controlado, que funciona como um Lixão, mas que possui uma estrutura para proteção da chuva, contudo sem preocupações com a disposição e os impactos causados a partir da decomposição dos resíduos nele depositados. A seguir algumas respostas que representam este tipo de relação.

R(22): "É onde despejam os resíduos em um lugar afastado."; R(40): "Uma porção de terra é retirada, há depositação de diversos resíduos que posteriormente é coberta.".

Dos respondentes, 6 apresentaram um significado para o conceito coerente com a literatura quanto à ideia de funcionamento e cuidados que um Aterro Sanitário necessita.

$\mathrm{R}(04)$ : "Soterramento de resíduos com a aplicação de processos de contenção para evitar contaminação.";

$\mathrm{R}(06)$ : "Lixo sob o solo, porém diferente do "lixão", visto que há cuidado maior no aterro sanitário, a fim de não prejudicar o solo.”;

Já para 16 alunos, o conceito estava relacionado à utilização desse tipo de destinação para prover apropriada disposição dos resíduos gerados pela população.

R(18): "É um local definido, onde são deixados os resíduos gerados por certa população.";

$\mathrm{R}(31)$ : "Onde é descartado os rejeitos da maioria da população.”.

A partir dos resultados obtidos nas questões acima apresentadas, identificou-se a necessidade de aperfeiçoamento dos conceitos sobre os diferentes tipos de tratamento dos resíduos químicos. Além disso, notou-se que a proposta de formação seria uma oportunidade para enculturação dos conceitos e discussão sobre as responsabilidades pelos resíduos químicos gerados nos laboratórios, assim como dos riscos destes para o ambiente. Também, para realizar a retroalimentação do tema gestão e tratamento de resíduos, para a formação de profissionais conscientes de suas atitudes tanto no seu ambiente laboral como fora dele. ${ }^{7,8,12}$

Considera-se que a linguagem escrita utilizada pelos estudantes para expressar seus conhecimentos espontâneos sobre a temática em discussão, oriunda dos saberes prévios relacionados aos aspectos intuitivos e empíricos, pode ser ampliada no sentido de se aproximar da linguagem científica. ${ }^{18}$

De acordo com Tozoni-Reis, ${ }^{17}$ acredita-se que apenas por meio de uma rigorosa e densa reflexão dos princípios teóricos da EA, seremos capazes de problematizar as práticas educativas e as tendências teóricas, para que a reflexão oportunize mudanças concretas na organização social a fim de mitigar as problemáticas ambientais.

\section{Diagnóstico final}

Após o período de formação, o Questionário Final utilizado para realizar o diagnóstico final foi aplicado como última etapa da pesquisa com o grupo de alunos. Essa ferramenta foi utilizada ao final do semestre, o que pode explicar o fato de ter ocorrido o não comparecimento de 20 alunos em comparação ao número de respondentes 


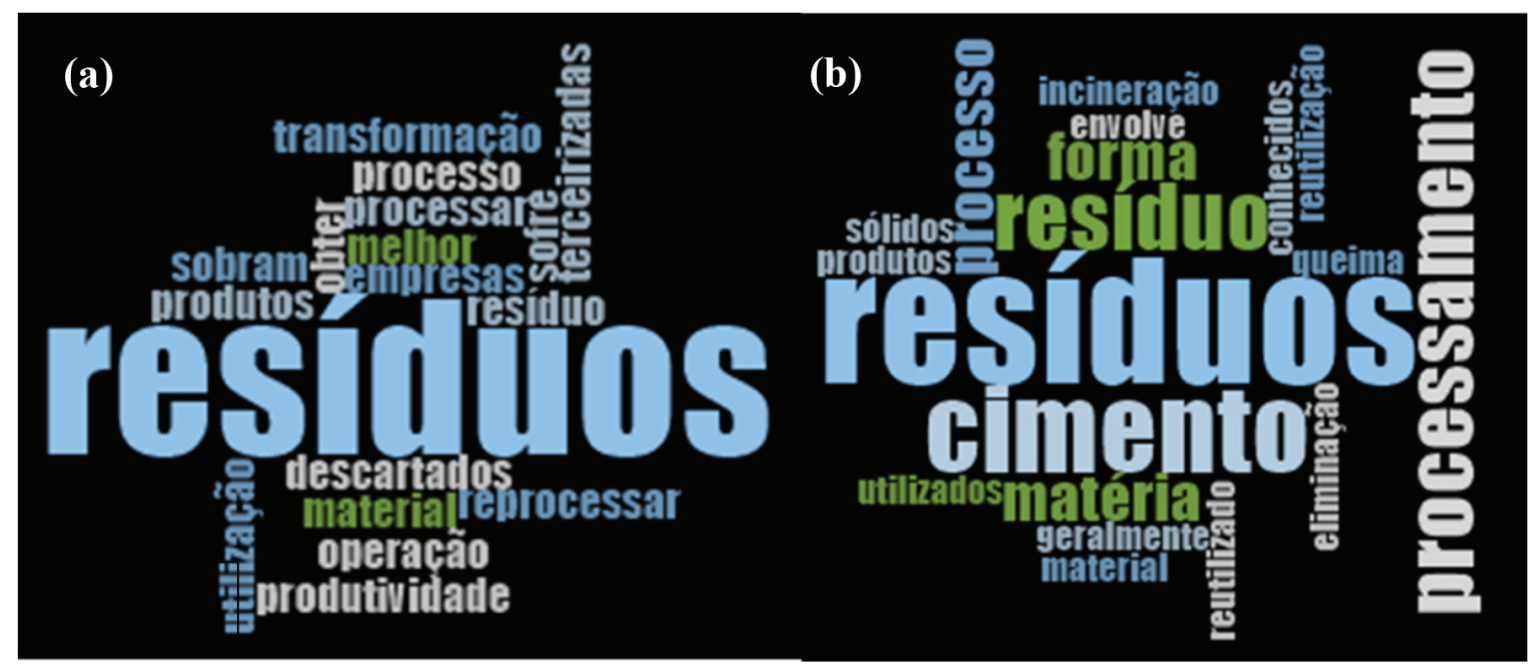

Figura 1. Imagens NVivo $12^{\circledR}$ para Coprocessamento: (a) Questionário Inicial; (b) Questionário Final

no instrumento inicial (66). No total, 46 sujeitos responderam o referido questionário.

Para verificar o nível de alfabetização científica representada pelas respostas dos alunos, foram expostas as imagens obtidas a partir do software NVivo $12 \AA$, nas quais destacam-se os termos de maior frequência.

Utilizando as imagens de representação e visualização dos dados geradas com o software NVivo $12 ®$ (Figura 1), verifica-se indícios para a enculturação do conceito de coprocessamento. As imagens geradas pelo software, a partir da frequência de aparição de termos nas respostas, aponta para a apropriação dos conceitos trabalhados na atividade formativa, visto que os termos em tamanho maior estão mais relacionados aos princípios fundamentais do tratamento do tipo coprocessamento. Destaca-se o termo "cimento". Algumas matérias-primas podem ser substituídas ou misturadas com o subproduto gerado no processo de Coprocessamento na fabricação do cimento. Esta evolução conceitual pode ser identificada com a análise da Figura 1.

A partir da classificação realizada para analisar as respostas dos sujeitos sobre o Coprocessamento, é possível perceber que houve um aumento de 8 respondentes que apresentaram significados para o conceito que convergem com aqueles encontrados na literatura (Tabela 1). Nesse contexto pode-se observar que as respostas foram aperfeiçoadas, apontando que a ação de formação contribuiu para pluralizar os conhecimentos iniciais dos estudantes sobre esse conceito. O que pode ser evidenciado com o aumento no número de respondentes que afirmaram conhecer o tratamento Coprocessamento, posto que passaram de 4 alunos no questionário inicial (6\% do total de 66 respondentes) para 12 alunos no questionário final (26\% do total de 46 respondentes), conforme Tabela 1.

Tabela 1. Respostas sobre Coprocessamento nos instrumentos de diagnóstico inicial e final

\begin{tabular}{|c|c|c|c|c|}
\hline \multirow{2}{*}{ Tratamento } & \multirow{2}{*}{\multicolumn{2}{|c|}{ Resposta }} & \multicolumn{2}{|c|}{ Frequência $/ \mathrm{n}^{\circ}$ respondentes } \\
\hline & & & Inicial & Final \\
\hline \multirow{5}{*}{$\begin{array}{l}\text { Coprocessa- } \\
\text { mento }\end{array}$} & \multirow{3}{*}{ Sim } & Convergente & $2 / 66$ & $10 / 46$ \\
\hline & & Divergente & $2 / 66$ & $2 / 46$ \\
\hline & & Branco & $-\mathrm{x}-$ & $4 / 46$ \\
\hline & \multicolumn{2}{|c|}{ Não conhecem } & $62 / 66$ & $27 / 46$ \\
\hline & \multicolumn{2}{|c|}{ Não responderam } & $-x-$ & $3 / 46$ \\
\hline
\end{tabular}

Com respeito à Incineração, no questionário final, 42 (91\%) dos 46 sujeitos responderam conhecer esse tratamento. Se comparado ao questionário inicial, onde 49 (74\%) dos 66 respondentes afirmaram ter conhecimento, evidencia-se um crescimento proporcional em termos de alunos que conceituaram Incineração de forma coerente ao conceito científico. Destacando-se as seguintes respostas apresentadas pelos estudantes:

$\mathrm{R}(28)$ : "Queima dos resíduos, diminui o volume de resíduo e transforma em espécies menos perigosas.";

$\mathrm{R}(41)$ : "Utilização do calor para conter um composto halogenado.".

Considerando Incineração como o processo pelo qual os resíduos químicos, classificados como classe I, são decompostos por oxidação térmica a altas temperaturas e com controle dos gases emitidos, verificou-se que as respostas contemplaram termos correspondentes usualmente para definir esse tratamento, de acordo com a imagem gerada no NVivo 12® (Figura 2) e dados coletados através da classificação das respostas (Tabela 2).

Na imagem da Figura 2 destaca-se o uso mais frequente de termos como "temperaturas" e "altas", condições utilizadas no processo de Incineração. A partir da classificação realizada para analisar a enculturação dos significados dos conceitos envolvidos na Incineração, é possível perceber que houve um aumento de 7 respondentes que apresentaram conceitos que convergem com aqueles encontrados na literatura (Tabela 2).

Para o tratamento que utiliza Aterros Sanitários como forma de disposição final, 42 alunos (91\%) dos 46 sujeitos responderam conhecer este processo, evidenciando o crescimento por parte do grupo pesquisado quanto à compreensão do significado para o conceito desta técnica, pois no questionário inicial $56(81 \%)$ dos 66 respondentes apontaram conhecer. Porém no questionário final, 6 estudantes não escreveram nenhum conceito para o tratamento, além de dois alunos não responderem à questão. Observa-se que com as 36 respostas apresentadas no questionário final foi possível identificar a elaboração de respostas com maior proximidade àquela encontrada na literatura, o que pode indicar a apropriação do conceito, como ilustra-se.

R (03): "Depositar o lixo sob o solo, porém com cuidados para que o lixo não contamine o solo.";

$\mathrm{R}$ (04): "Enterrar o resíduo e deixar decompor naturalmente com o devido monitoramento (coleta dos gases, lona impermeável para não contaminar as fontes hídricas).”; 

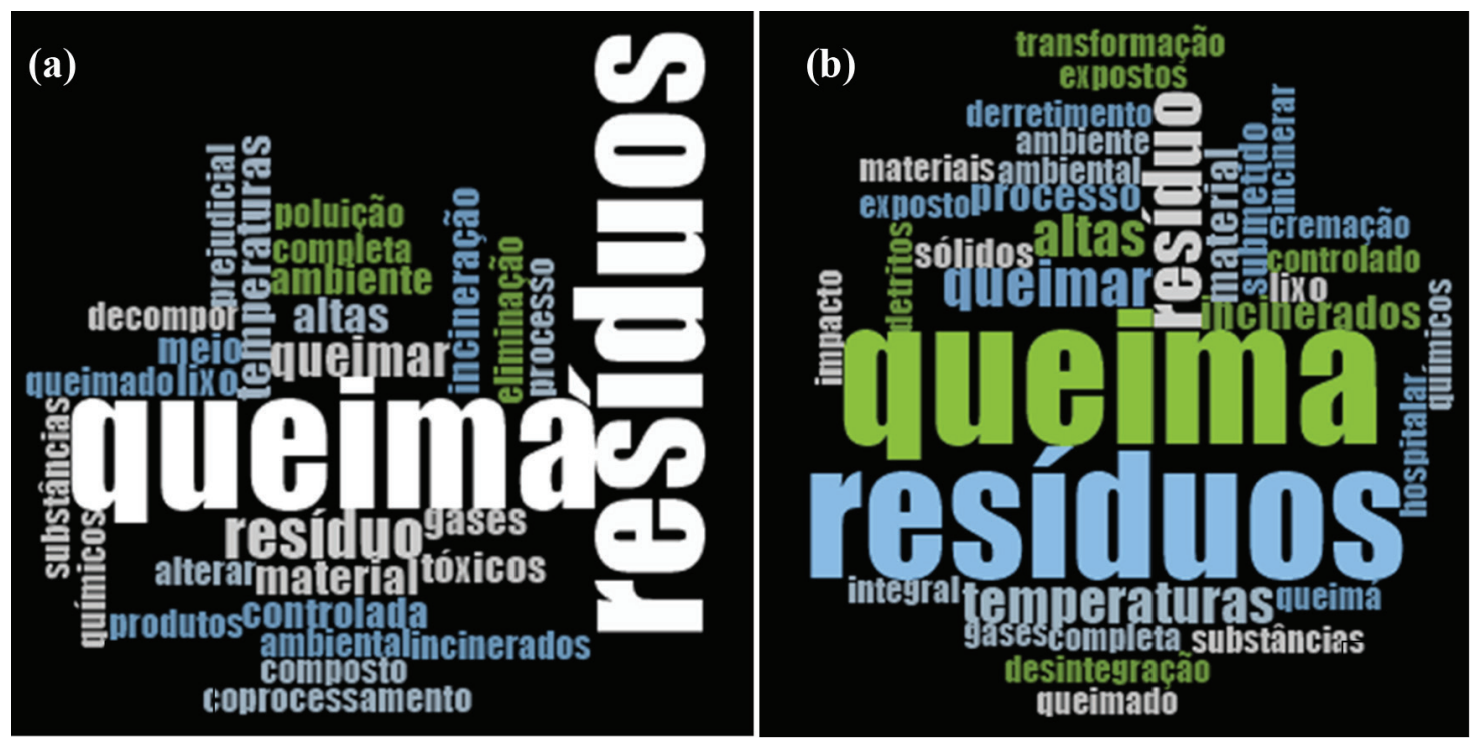

Figura 2. Imagens NVivo $12^{\circledR}$ para Incineração: (a) Questionário Inicial; (b) Questionário Final

Tabela 2. Respostas sobre Incineração nos instrumentos de diagnóstico inicial e final.

\begin{tabular}{|c|c|c|c|c|}
\hline \multirow{2}{*}{ Tratamento } & \multirow{2}{*}{\multicolumn{2}{|c|}{ Resposta }} & \multicolumn{2}{|c|}{ Frequência/ $\mathrm{n}^{\circ}$ respondentes } \\
\hline & & & Inicial & Final \\
\hline \multirow{5}{*}{ Incineração } & \multirow{3}{*}{ Sim } & Convergente & $11 / 66$ & $18 / 46$ \\
\hline & & Divergente & $37 / 66$ & $23 / 46$ \\
\hline & & Branco & $1 / 66$ & $1 / 46$ \\
\hline & \multicolumn{2}{|c|}{ Não conhecem } & $17 / 66$ & $3 / 46$ \\
\hline & \multicolumn{2}{|c|}{ Não responderam } & $-x-$ & $1 / 46$ \\
\hline
\end{tabular}

Esse conjunto de respostas gerou uma imagem no NVivo 12® (Figura 3), na qual destacam-se termos como "camadas", "depósito", "sólidos" relacionados às características dos Aterros Sanitários. Além disso, identificou-se na imagem inicial uma dispersão de ideias, enquanto na final uma convergência ao significado do conceito encontrado na literatura.

A partir da classificação feita das respostas dadas pelos estudantes (Tabela 3), percebe-se que a proporção de respostas coerentes aos conceitos científicos aumentaram proporcionalmente, pois no questionário inicial $32(48 \%)$ dos 66 estudantes apresentaram respostas
Tabela 3. Respostas sobre Aterro Sanitário nos instrumentos de diagnóstico inicial e final

\begin{tabular}{|c|c|c|c|c|}
\hline \multirow{2}{*}{ Tratamento } & \multirow{2}{*}{\multicolumn{2}{|c|}{ Resposta }} & \multicolumn{2}{|c|}{ Frequência/n ${ }^{\circ}$ respondentes } \\
\hline & & & Inicial & Final \\
\hline \multirow{5}{*}{$\begin{array}{l}\text { Aterro } \\
\text { sanitário }\end{array}$} & \multirow{3}{*}{ Sim } & Convergente & $32 / 66$ & $24 / 46$ \\
\hline & & Divergente & $16 / 66$ & $12 / 46$ \\
\hline & & Branco & $6 / 66$ & $6 / 46$ \\
\hline & \multicolumn{2}{|c|}{ Não conhecem } & $12 / 66$ & $2 / 46$ \\
\hline & \multicolumn{2}{|c|}{ Não responderam } & $-x-$ & $2 / 46$ \\
\hline
\end{tabular}

com esse perfil, enquanto que no final 24 (52\%) dos 46 respondentes, apontando uma amplicação na rede conceitual dos estudantes.

Frente ao conjunto de dados, percebe-se que com a maior parte dos estudantes foi possível observar a apliação da rede de conceitos referentes aos tratamentos que foram discutidos na ação de formação, ou seja, a enculturação $0^{23}$ desses conceitos. Com as imagens e respostas apresentadas acima, exemplifica-se esse processo, pois as respostas identificadas no questionário final apresentam significados mais convergentes aos aportes da literatura. É pertinente salientar que o objetivo da atividade formativa não foi de identificar

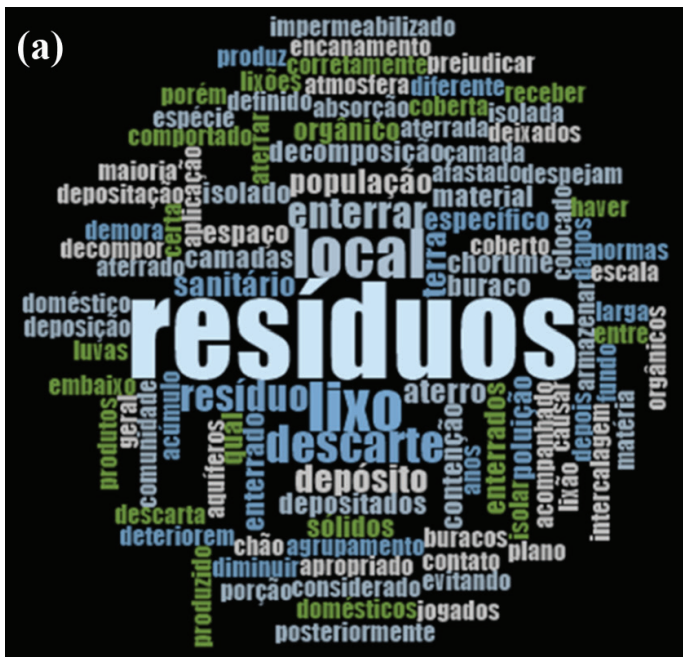

(b)

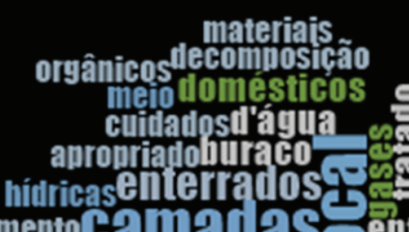

soterramento
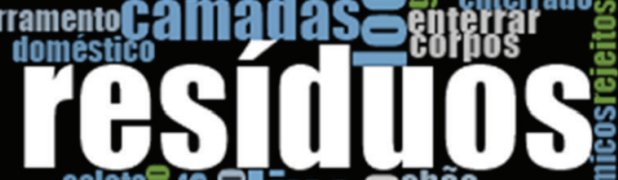

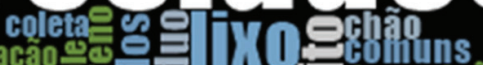

liberacao

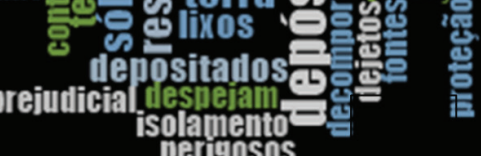

oreiudicial despejam perigosos

Figura 3. Imagens NVivo $12^{\circledR}$ para Aterro Sanitário: (a) Questionário Inicial; (b) Questionário Final 
os conhecimentos prévios dos estudantes, para depois substituí-los pelo conhecimento científico, mas sim o de buscar aperfeiçoá-los. Ademais, no curso buscou-se discutir sobre os conceitos dos diferentes tipos de tratamento relacionando-os ao contexto da disciplina, do curso e das futuras áreas de atuação dos profissionais da química, para não recair numa perspectiva ingênua de incorporação vazia de palavras aos significados dos conceitos. ${ }^{20}$

Dessa forma, considera-se que a atividade formativa contribuiu para que os estudantes se apropriassem dos conceitos formais apresentados e discutidos com o grupo. Pensar a qualificação de futuros profissionais, com ênfase na educação ambiental crítica, pode permitir a reorientação de concepções e práticas dos profissionais da área de química com o intuito de guiar ações sociais e culturais para melhor qualidade de vida. ${ }^{18,19}$

\section{CONCLUSÕES}

O presente trabalho buscou avaliar a partir dos resultados obtidos através dos instrumentos de diagnóstico inicial e final, se os estudantes dos cursos de Bacharelado em Química, Química Industrial e Engenharia Química da UFRGS, que participaram desta pesquisa, apresentaram aperfeiçoamento de conceitos relacionados ao tratamento de resíduos químicos. Por se tratar de conceitos pertinentes à formação de profissionais da área da química, assim como para sua vida pessoal, foi realizada, com as turmas pesquisadas, uma atividade de formação com o propósito de discutir conceitos e procedimentos envolvidos na gestão e tratamento dos resíduos químicos, além de questões culturais, sociais e ecônomicas não discutidas neste trabalho.

A disciplina escolhida para aplicação da presente investigação e realização da atividade formativa foi a Química Geral Experimental (QUI01003). Essa escolha ocorreu por ser uma disciplina em que se desenvolvem ações desta natureza desde a década de $1990,{ }^{7}$ além da necessidade de realizar a retroalimentação dos conceitos necessários para compreensão e reflexão dos alunos quanto aos resíduos químicos que são gerados tanto nos laboratórios de ensino e pesquisa, como aqueles resíduos produzidos ao longo das atividades profissionais e pessoais. ${ }^{12}$

Com a ação de formação, teve-se juntamente o objetivo de despertar a curiosidade e interesse nos estudantes com respeito a esta temática. Para tal, buscou-se realizar uma atividade que estivesse corroborando com a prática da Educação Ambiental Crítico-Transformadora ${ }^{5,17}$ e que, ao analisar as respostas dadas ao questionário inicial e ao questionário final, consiga ser evidenciado se ocorreu a enculturação dos conceitos trabalhados na formação por parte dos estudantes. ${ }^{23}$

Verificou-se, a partir dos resultados apresentados, que a abordagem proposta no presente estudo favoreceu a tomada de consciência e a evolução conceitual dos estudantes da graduação, que participaram da pesquisa, sobre gestão e tratamento de resíduos químicos. Podese inferir também que a atividade de formação oferecida aos alunos contribuiu para a formação tanto profissional, como social dos alunos, aperfeiçoando conceitos e valores necessários para serem aplicados em suas futuras práticas profissionais, assim como conscientizando sobre a importância dos processos de gestão e tratamento de resíduos químicos.

Destaca-se que, para o tratamento Coprocessamento, o processo de enculturação foi identificado na escrita dos significados do conceito de forma mais evidente, assim como no número de respondentes que apontaram conhecê-lo no questionário final. Para os outros dois tipos de tratamento, a enculturação dos conceitos também foi identificada, mesmo que de forma não tão evidente.

A ação desenvolvida neste trabalho foi pensada visando o aprimoramento e afrontamento com a temática ambiental já no início de curso, como forma de possibilitar a aproricação crítica e reflexiva ${ }^{17}$ dos conceitos e práticas desenvolvidas nos laboratórios de ensino. Todavia, entende-se que é necessário um conjunto de outras ações para que os objetivos da EA crítica sejam contemplados e que o aluno egresso tenha aporte suficiente para ser um sujeito atuante e responsável por práticas cidadãs, tanto no seu ambiente de trabalho como fora dele. Como exemplo destaca-se a inserção dos tópicos sobre gestão e tratamento de resíduos no material utilizado em sala de aula e de questionamentos norteadores sobre o tema para fomentar à discussão durante o semestre letivo, para poder favorecer o processo de alfabetização científica dos estudantes, contemplando assim os objetivos deste trabalho. Essa sugestão foi efetivada desde o segundo semestre de 2019, a partir dos dados produzidos com esta pesquisa e das reuniões realizadas com os professores que ministram a referida disciplina. Além disso, são necessários grupos de discussão entre estudantes e professores, ${ }^{1,2}$ reavaliação de roteiros de práticas e reagentes das demais disciplinas dos cursos de Química, ${ }^{3}$ assim como uma análise criteriosa das ações formativas desenvolvidas com essa natureza.

\section{REFERÊNCIAS}

1. Pence, L. E.; Kirchhoff, M. M.; J. Chem. Educ. 2013, 90, 510.

2. Montañés, M. T.; Palomares, A. E.; Sánchez-Tovar, R.; Chem. Educ. Res. Pract. 2012, 13, 128.

3. Ramm, J. G.; Dorscheid, G. L.; Passos, C. G.; Sirtori, C.; J. Chem. Educ. 2018, 95, 570 .

4. Di Vitta, C.; Martins, C. R.; Di Vitta, P. B.; Marzorati, L.; Quim. Nova 2017, 40, 214.

5. Tozoni-Reis, M. F. C.; Pesquisa em Educação Ambiental, 2008, 3, 155.

6. http://www.refworld.org/docid/57b6e3e44.html, acessada em Janeiro 2020.

7. Amaral, S. T.; Machado, P. F. L.; Peralba, M. C. R.; Camara, M. R.; Santos, T.; Berleze, A. L.; Falcão, H. L.; Martinelli, M.; Gonçalves, R. S.; Oliveira, E. R.; Brasil, J. L.; Araújo, M. A.; Borges, A. C. A.; Quim. Nova 2001, 24, 419.

8. Gerbase, A. E.; Coelho, F. S.; Machado, P. F. L.; Ferreira, V. F.; Quim. Nova 2005, 18, 3.

9. Pergher, S. B. C.; Demaman, A. S.; Funk, S.; Hepp, L. U.; Adário, A. M. dos S.; Quim. Nova 2004, 27, 674.

10. Tavares, G. A.; Bendassolli, J. A.; Quim. Nova 2005, 28, 732.

11. Alberguini, L. B. A.; Silva, L. C.; Rezende, M. O. O.; Quim. Nova 2003, 26, 291.

12. Jardim, W. de F.; Quim. Nova 1998, 21, 671.

13. http://www.planalto.gov.br/ccivil_03/constituicao/ constituicaocompilado.htm, acessada em Março 2019.

14. http://www.planalto.gov.br/ccivil_03/leis/L9605.htm, acessada em Janeiro 2020.

15. http://www.mma.gov.br/estruturas/educamb/_arquivos/pronea3.pdf, acessada em Março 2019.

16. http://conferenciainfanto.mec.gov.br/images/conteudo/iv-cnijma/ diretrizes.pdf, acessada em Março 2019.

17. Loureiro, C. F. B.; Tozoni-Reis, M. F. C.; Revista Eletrônica do Mestrado em Educação Ambiental, 2016, 33, 68.

18. Chassot, A. Alfabetização científica: questões e desafios para educação, $5^{\mathrm{a}}$ ed., Editora Unijuí: Ijuí, 2010.

19. Costa, L. S. O.; Echeverría, A. R.; Ribeiro, F. L.; Revista Brasileira de Pesquisa em Educação em Ciências, 2017, 17, 803.

20. Vigotski, L. S. A construção do pensamento e da linguagem. Martins Fontes: São Paulo, 2001.

21. Associação Brasileira de Normas Técnicas. ABNT/NBR 10004: Resíduos Sólidos - Classificação. Rio de Janeiro/RJ, 2004, 71. 
22. http://www.iq.ufrgs.br/cgtrq/index.php/institucional, acessada em Janeiro 2020

23. Driver, R.; Asoko, H.; Leach, J.; Mortimer, E. F.; Scott, P.; Quim. Nova Esc. 1999, 9, 31.

24. Amaral, E. M. R.; Mortimer, E. F. Em A pesquisa em ensino de ciências no Brasil e suas metodologias; dos Santos, F. M. T., Greca, I. M., orgs.; $1^{\text {a }}$ ed., Editora Unijuí: Ijuí, 2006, pp. 239-296.

25. Sasseron, L. H.; Carvalho, A. M. P.; Investigações em Ensino de Ciências (Online), 2011, 16, 59.
26. Günther, H.; Psicologia: Teoria e Pesquisa 2006, 22, 201.

27. Cavalcanti, V. O. De, Neta, O. M. de M., Cavalcanti, I. S. S.; Nascimento, B. L. C.; Anais eletrônicos do Encontro Ibérico EDICIC, Coimbra, Portugal, 2017.

28. Mazzer, C.; Cavalcanti, O. A.; Infarma 2004, 16, 67.

29. http://www.planalto.gov.br/ccivil_03/_ato2007-2010/2010/lei/112305. htm, acessada em Janeiro 2020. 